\title{
Routine beta-blocker administration following acute myocardial infarction: why still an unsolved issue?
}

\author{
Stephane Noble, Marco Roffi \\ Division of Cardiology, Geneva University Hospitals, Geneva, Switzerland \\ Correspondence to: Prof. Marco Roffi, MD. Division of Cardiology, Geneva University Hospitals, 4 Rue Gabrielle-Perret-Gentil, 1205 Geneva, \\ Switzerland. Email: Marco.Roffi@hcuge.ch. \\ Provenance: This is an invited Editorial commissioned by the Section Editor Hai-Long Dai (Department of Cardiology, Yan'an Affiliated Hospital of \\ Kunming Medical University, Kunming, China). \\ Comment on: Dondo TB, Hall M, West RM, et al. $\beta$-Blockers and Mortality After Acute Myocardial Infarction in Patients Without Heart Failure or \\ Ventricular Dysfunction. J Am Coll Cardiol 2017;69:2710-20.
}

Submitted Sep 16, 2017. Accepted for publication Oct 01, 2017.

doi: $10.21037 /$ jtd.2017.10.25

View this article at: http://dx.doi.org/10.21037/jtd.2017.10.25

Since the 1980s, the mortality from myocardial infarction (MI) has regressed by approximately $25 \%$ in Western countries, not only due to the development of routine defibrillation, monitored units and early coronary reperfusion but also to the introduction of antiplatelet therapies, angiotensin-converting enzyme (ACE) inhibitors/ angiotensin-receptor blockers (ARBs), statins and betablockers. The reperfusion era started in the 1980s, when thrombolytic therapy gained wide acceptance in STsegment elevation myocardial infarction (STEMI) after several randomized controlled trials showed reduced mortality and better preservation of left ventricular ejection fraction (LVEF) with thrombolysis over standard treatment. Thereafter, randomized studies performed from the late 1990 s and aggregated in the meta-analysis of Keeley in 2003 (1), showed the superiority of primary percutaneous coronary intervention (PPCI) over thrombolysis in STEMI. According to recent guidelines, PPCI is the treatment of choice for STEMI, when available in a maximum expected delay from diagnosis to wire crossing the lesion of 120 minutes (ideally 90 minutes for transferred patients and 60 minutes for patients presenting at PPCI centers) (2). An early invasive approach-defined as coronary angiography within 24 hours of first medical contact-is recommended for non-ST segment elevation MI (NSTEMI) (3).

Since the first studies showing a survival benefit of betablockers in patients with non-reperfused acute MI $(4,5)$, timely reperfusion has changed the landscape not only because of a reduction in early mortality and mechanical complications, but also because of more favorable myocardial healing and remodeling, translating into improved LVEF, less heart failure, and a myocardium less vulnerable to arrhythmias. Beta-blockers slow heart rate and have a negative inotropic effect, leading to a reduction in myocardial oxygen consumption and increasing the threshold to myocardial ischemia. In chronic stable angina, the efficacy of beta-blockers in reducing angina and complications of myocardial ischemia including infarction, arrhythmias and sudden death has been shown in randomized trials $(6,7)$. In this respect, it has been hypothesized that the decrease in out-of-hospital ventricular fibrillation and the increase in out-of-hospital pulseless electrical activity/asystole observed in Holland over the last 10 years is related to long term post-MI treatment with beta-blockers and intracardiac defibrillators (8). In post MI patients with a LVEF $\leq 40 \%$ or heart failure-in the absence of contraindications such as acute heart failure, hemodynamic instability or high degree AV block-beta-blockers have a class I indication (9). Indeed, in 2001 the Carvedilol Post-Infarct Survival Control in LV Dysfunction (CAPRICORN) (10) triala randomized study comparing carvedilol to placebo in a post-MI population with half of the patients reperfused and a LVEF $\leq 40 \%$-demonstrated a $23 \%$ reduction in allcause mortality with beta-blockers at 2.5 years. Clopidogrel and Metoprolol in Myocardial Infarction Trial (COMMIT) randomized 45,852 Chinese patients with acute MI (STEMI, left-bundle branch block, or ST depression) within 24 hours of symptom onset and regardless of 
the LVEF, to metoprolol (intravenous administration followed by $200 \mathrm{mg}$ per os daily) or placebo (11). The vast majority of patients did not undergo timely reperfusion. There was no mortality reduction with betablockers at 28 days. Patients treated with metoprolol had fewer reinfarction and ventricular fibrillation episodes, but the benefit was counterbalanced by an increase in cardiogenic shock. An excess in mortality in the active treatment arm was observed among patients who were hypotensive or in Killip class III.

There are several unanswered questions with respect to beta-blockers post MI, in particular the timing and duration of administration, the optimal dose and the benefit in patients with normal or mildly depressed LVEF. In animal models of acute MI, metoprolol markedly reduced infarct size when administered IV before reperfusion (12). The Early Intravenous Beta-Blockers in Patients With STsegment Coronary Intervention (EARLY-BAMI) trial (13)a double-blind randomized trial of IV metoprolol $(5 \mathrm{mg}$ at recruitment and $5 \mathrm{mg}$ before $\mathrm{PPCI}$ ) or placebo in more than 600 STEMI patients within $12 \mathrm{~h}$ of symptom onsetdid not show a reduction of MI size on magnetic resonance imaging (MRI), but beta-blockers significantly decreased the incidence of malignant arrhythmias in the acute phase in the absence of adverse events. Killip class III or IV, systolic blood pressure $<100 \mathrm{mmHg}$, heart rate $<60$ beats per min, type II or III AV blocks were all exclusion criteria for the study. The Effect of Metoprolol in Cardioprotection During an Acute Myocardial Infarction [METOCARDCNIC $(14,15)]$ trial—a randomized but not blinded nor placebo-controlled trial including 131 patients in the metoprolol $15 \mathrm{mg}$ arm and 130 in the control group who had anterior STEMI within 6 hours of symptom onset, were in Killip class I or II and had a systolic blood pressure $>120 \mathrm{mmHg}$ - did show smaller MI size on MRI and higher LVEF in the metoprolol arm at 5 to 7 days post MI with no excess of adverse events during the first 24 hours. All patients without contraindications received oral metoprolol within 24 hours. At 6-month follow-up, the early IV metoprolol group showed higher LVEF, reduced incidence of severe LV dysfunction as well as ICD indication. Furthermore, in the early IV metoprolol group there were fewer re-admissions for heart failure.

According to the latest ESC STEMI guidelines, IV beta-blockers at the time of presentation followed by oral treatment should be considered, in the absence of contraindications, in patients undergoing PPCI with no signs of acute heart failure (Killip class $\leq$ II) and a systolic blood pressure $>120 \mathrm{mmHg}$ [class IIa, level of evidence (LOE) B]. The 2013 ACC/AHA STEMI guidelines (16) recommend that beta-blockers should be started in the first $24 \mathrm{~h}$ in patients with STEMI (class I, LOE B), if there are no signs of heart failure, evidence of lowoutput state, increased risk for cardiogenic shock or other contraindications (PR interval $>0.24 \mathrm{~s}$, II or III degree heart block, active asthma, or reactive airways disease). In the ESC NSTEMI guidelines, early initiation of betablockers is recommended in patients with ongoing ischemic symptoms and in the absence of contraindications (class I, LOE B) (3). Furthermore, beta-blockers should not be administered in patients with possible coronary spasm or cocaine use since they might favor spasm by leaving alphamediated vasoconstriction unopposed by beta-mediated vasodilatation. In accordance with the guidelines, the prescription of beta-blockers in post-MI patients is high even in patients without LV dysfunction. A 2015 metaanalysis of 10 observational acute MI studies including more than 40,000 patients showed that beta-blockers reduced the risk of all-cause death (17). However, the benefit of these agents was not found in all subgroups and seemed confined to the patients with reduced LVEF, with low use of other secondary prevention drugs, or NSTEMI.

Dondo et al. tried to answer the question of the benefit of beta-blockers in patients post MI with no LV systolic dysfunction (18). They reported in the Journal of the American College of Cardiology earlier in 2017 the impact of the use of beta-blockers on all-cause mortality at 1-year in MI survivors without heart failure or LV systolic dysfunction in the United Kingdom national heart attack register, known as Myocardial Ischaemia National Audit Project (MINAP). Data were prospectively collected at each hospital between January 2007 and June 2013, and transferred online (encrypted) to a central database. Strengths of the study included the large sample size (analytic cohort of 179,810 patients) and the broad use of evidence-based treatments (revascularization rate $>50 \%$, $>90 \%$ dual antiplatelet therapy, $>80 \%$ ACEI/ARBs, $>80 \%$ participating in a rehabilitation program, $95 \%$ received beta-blockers). A higher unadjusted mortality rate at one year was observed in the patients not receiving betablockers (4.9\% vs. 11.2\%). However, in a propensity score analysis including 24 variables, there was no difference in mortality in patients discharged with or without betablockers.

These data should be interpreted with great caution. First it may be argued that the two groups (no beta- 
blocker $v s$. beta-blocker) may not be at all comparable, despite the statistical adjustments. Indeed, the populations were imbalanced in terms of size $(5 \%$ vs. $95 \%$ of the cohort, respectively) and major differences were present in the baseline characteristics (e.g., mean age difference between the groups $>5$ years). Furthermore, patients not receiving or receiving beta-blockers were managed differently with respect to all the other evidence-based therapies (i.e., aspirin, $\mathrm{P} 2 \mathrm{Y}_{12}$ inhibitors, ACE inhibitors, statins, coronary angiography, revascularization as well as cardiac rehabilitation). Therefore, it might not be surprising that the one-year mortality rates of patients not treated $v s$. treated with beta-blockers were not in the same range. Multivariable/propensity score analyses may have incompletely adjusted for the differences and there may have been unmeasured co-variates affecting mortality. In this setting, adjustment with sophisticated statistical methods may have been methodologically sound but clinically questionable. Second, patients with a LVEF from $30 \%$ to $40 \%$, for whom there are clear benefits in prescribing betablockers, were included in the study. Third, no information on adherence to beta-blocker treatment was available, as the prescription of beta-blockers was recorded only at hospital discharge. In this respect, the Outcomes of Beta-blockers Therapy After Myocardial Infarction [OBTAIN (19)] study - a North American registry of more than 7,000 patients with acute MI-showed that at 2 years, $20 \%$ of the patients on beta-blockers had a lower dose than at discharge, $54 \%$ had the same dose, $3.8 \%$ had discontinued their treatment and the mean overall dose was $38 \%$ of the optimal dose.

The issue of the efficacy of beta-blockers in patients with preserved/mildly reduced LV function is one of the major gaps in evidence in post MI management. Let's just think at the potential impact on male patients with respect to erectile dysfunction while in both genders it may be challenging to differentiate post-MI fatigue or even depression from a potential side-effect of this class of agents (20-23). The results of the study from Dondo et al. are to be considered hypothesis-generating and not sufficient to change practice. In the era of PPCI, there may be little room for further risk reduction in patients post MI with normal LVEF in the presence of guideline-based therapy with antiplatelet treatment, statins, and ACE inhibitors/ARBs. Randomized studies assessing the efficacy of beta-blockers on mortality in patients with normal or slightly decreased LVEF are lacking. Given the low likelihood that the pharmaceutical industry will ever fund an adequately powered clinical trial in the field-because of the lack of return on investmentit is up to individual investigators, medical societies, public funds or foundations to invest time, energy, and money in this endeavor. Should this issue ever be solved, the next in line for post-MI patients would be the optimal duration of beta-blocker treatment.

\section{Acknowledgements}

None.

\section{Footnote}

Conflicts of Interest: The authors have no conflicts of interest to declare.

\section{References}

1. Keeley EC, Boura JA, Grines CL. Primary angioplasty versus intravenous thrombolytic therapy for acute myocardial infarction: a quantitative review of 23 randomised trials. Lancet 2003;361:13-20.

2. Ibanez B, James S, Agewall S, et al. 2017 ESC Guidelines for the management of acute myocardial infarction in patients presenting with ST-segment elevation: The Task Force for the management of acute myocardial infarction in patients presenting with ST-segment elevation of the European Society of Cardiology (ESC). Eur Heart J 2017. [Epub ahead of print].

3. Roffi M, Patrono C, Collet JP, et al. 2015 ESC Guidelines for the management of acute coronary syndromes in patients presenting without persistent ST-segment elevation: Task Force for the Management of Acute Coronary Syndromes in Patients Presenting without Persistent ST-Segment Elevation of the European Society of Cardiology (ESC). Eur Heart J 2016;37:267-315.

4. Norwegian Multicenter Study Group. Timolol-induced reduction in mortality and reinfarction in patients surviving acute myocardial infarction. $\mathrm{N}$ Engl J Med 1981;304:801-7.

5. A randomized trial of propranolol in patients with acute myocardial infarction. I. Mortality results. JAMA 1982;247:1707-14.

6. von Arnim T. Medical treatment to reduce total ischemic burden: total ischemic burden bisoprolol study (TIBBS), a multicenter trial comparing bisoprolol and nifedipine. The TIBBS Investigators. J Am Coll Cardiol 1995;25:231-8.

7. Fox KM, Mulcahy D, Findlay I, et al. The Total Ischaemic 
Burden European Trial (TIBET). Effects of atenolol, nifedipine SR and their combination on the exercise test and the total ischaemic burden in 608 patients with stable angina. The TIBET Study Group. Eur Heart J 1996;17:96-103.

8. Hulleman M, Berdowski J, de Groot JR, et al. Implantable cardioverter-defibrillators have reduced the incidence of resuscitation for out-of-hospital cardiac arrest caused by lethal arrhythmias. Circulation 2012;126:815-21.

9. Ponikowski P, Voors AA, Anker SD, et al. 2016 ESC Guidelines for the diagnosis and treatment of acute and chronic heart failure: The Task Force for the diagnosis and treatment of acute and chronic heart failure of the European Society of Cardiology (ESC)Developed with the special contribution of the Heart Failure Association (HFA) of the ESC. Eur Heart J 2016;37:2129-200.

10. Dargie HJ. Effect of carvedilol on outcome after myocardial infarction in patients with left-ventricular dysfunction: the CAPRICORN randomised trial. Lancet 2001;357:1385-90.

11. Chen ZM, Pan HC, Chen YP, et al. Early intravenous then oral metoprolol in 45,852 patients with acute myocardial infarction: randomised placebo-controlled trial Lancet;366:1622-32.

12. Ibanez B, Prat-González S, Speidl WS, et al. Early metoprolol administration before coronary reperfusion results in increased myocardial salvage: analysis of ischemic myocardium at risk using cardiac magnetic resonance. Circulation 2007;115:2909-16.

13. Roolvink V, Ibáñez B, Ottervanger JP, et al. Early Intravenous Beta-Blockers in Patients With STSegment Elevation Myocardial Infarction Before Primary Percutaneous Coronary Intervention. J Am Coll Cardiol 2016;67:2705-15.

14. Ibanez B, Macaya C, Sánchez-Brunete V, et al. Effect of early metoprolol on infarct size in ST-segmentelevation myocardial infarction patients undergoing primary percutaneous coronary intervention: the Effect of Metoprolol in Cardioprotection During an Acute Myocardial Infarction (METOCARD-CNIC) trial.

Cite this article as: Noble S, Roffi M. Routine beta-blocker administration following acute myocardial infarction: why still an unsolved issue? J Thorac Dis 2017;9(11):4191-4194. doi: $10.21037 /$ jtd.2017.10.25
Circulation 2013;128:1495-503.

15. Pizarro G, Fernández-Friera L, Fuster V, et al. Long-term benefit of early pre-reperfusion metoprolol administration in patients with acute myocardial infarction: results from the METOCARD-CNIC trial (Effect of Metoprolol in Cardioprotection During an Acute Myocardial Infarction). J Am Coll Cardiol 2014;63:2356-62.

16. American College of Emergency Physicians, Society for Cardiovascular Angiography and Interventions, O'Gara PT, et al. 2013 ACCF/AHA guideline for the management of ST-elevation myocardial infarction: executive summary: a report of the American College of Cardiology Foundation/American Heart Association Task Force on Practice Guidelines. J Am Coll Cardiol 2013;61:485-510.

17. Huang BT, Huang FY, Zuo ZL, et al. Meta-Analysis of Relation Between Oral $\beta$-Blocker Therapy and Outcomes in Patients With Acute Myocardial Infarction Who Underwent Percutaneous Coronary Intervention. Am J Cardiol 2015;115:1529-38.

18. Dondo TB, Hall M, West RM, et al. $\beta$-Blockers and Mortality After Acute Myocardial Infarction in Patients Without Heart Failure or Ventricular Dysfunction. J Am Coll Cardiol 2017;69:2710-20.

19. Goldberger JJ, Bonow RO, Cuffe M, et al. Effect of Beta-Blocker Dose on Survival After Acute Myocardial Infarction. J Am Coll Cardiol 2015;66:1431-41.

20. Gür Ö, Gurkan S, Yumun G, et al. The Comparison of the Effects of Nebivolol and Metoprolol on Erectile Dysfunction in the Cases with Coronary Artery Bypass Surgery. Ann Thorac Cardiovasc Surg 2017;23:91-5.

21. Ko DT, Hebert PR, Coffey CS, et al. Beta-blocker therapy and symptoms of depression, fatigue, and sexual dysfunction. JAMA 2002;288:351-7.

22. Ko DT, Hebert PR, Krumholz HM. Review: Beta-blockers increase fatigue and sexual dysfunction but not depression after myocardial infarction. ACP J Club 2003;138:30.

23. Ko DT, Hebert PR, Coffey CS, et al. Adverse effects of beta-blocker therapy for patients with heart failure: a quantitative overview of randomized trials. Arch Intern Med 2004;164:1389-94. 